\title{
Endoscopic resection of a large tongue-like esophageal mass: a rare case of esophageal striated muscle tumor
}

A 69-year-old man with significant symptoms of progressive dysphagia and mass regurgitation for 3 months sought therapy in our hospital. An outpatient computed tomography (CT) scan showed dilatation of upper esophagus with a shadow of soft-tissue density. A further enhanced CT of the chest showed a columnar mass in the esophagus of about $17.9 \mathrm{~cm}$, with mixed-density shadowing and heterogeneous enhancement (> Fig.1). With a diagnosis of giant hamartoma suspected, endoscopy was recommended, the results of which showed the mass was originating from the cervical esophagus (at $15 \mathrm{~cm}$ from the incisors), being linked by a long stalk, with the body of the mass free within the lumen ( $\triangleright$ Fig. 2). The mucosa of the stalk was intact and, after multidisciplinary consultation, we decided to remove the mass by endoscopic submucosal dissection (ESD). Ring marks were made on the mucosa at the base of the stalk using argon plasma coagulation, and submucosal injection was performed to create a bulge, after which the mucosa was dissected using a HybridKnife. Because of the huge volume of the mass, it had to be separated into several pieces using hot snare resection, which were then all retrieved through the mouth. The total volume of the mass after its removal was $13 \times 11 \times 2.8 \mathrm{~cm}$ ( $\triangleright$ Video 1 ). Immunohistochemistry and histologic results suggested the mass was a striated muscle tumor with undetermined malignant potential (> Fig.3). The patient subsequently attended for a follow-up endoscopy after 1 year, at which there was no evidence of recurrence, and there have been no post-procedure complications such as stenosis.

Mesenchymal tumors occurring in the esophagus are rare. The clinical diagnosis of esophageal rhabdomyoma is very difficult to make and lacks specific clinical manifestations [1]. This patient had a specific symptom that was similar to an
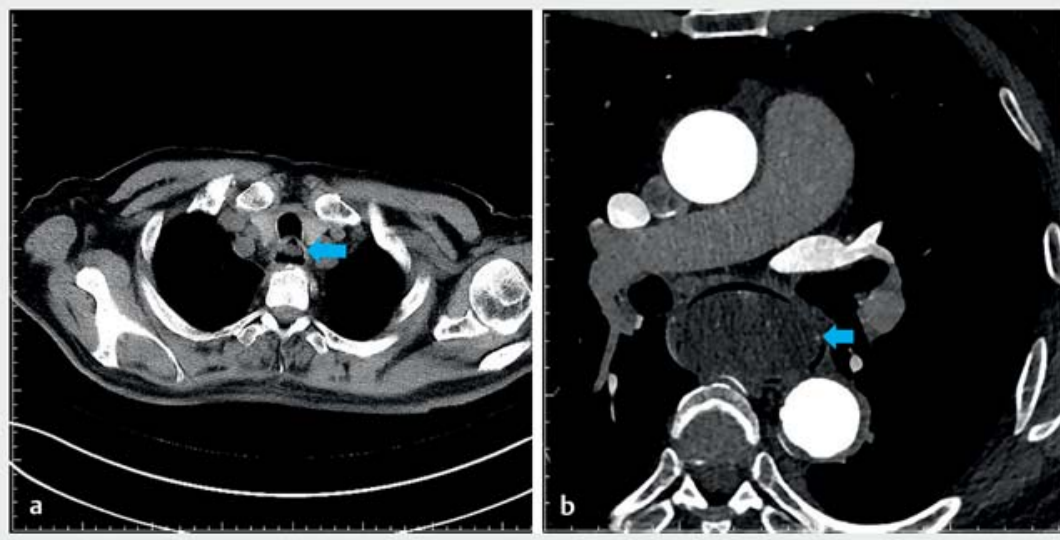

- Fig. 1 Computed tomography images showing: a the mass originating from the cervical esophagus to which it was linked by a stalk (blue arrow); $\mathbf{b}$ mixed density and heterogeneous enhancement of the mass (blue arrow).
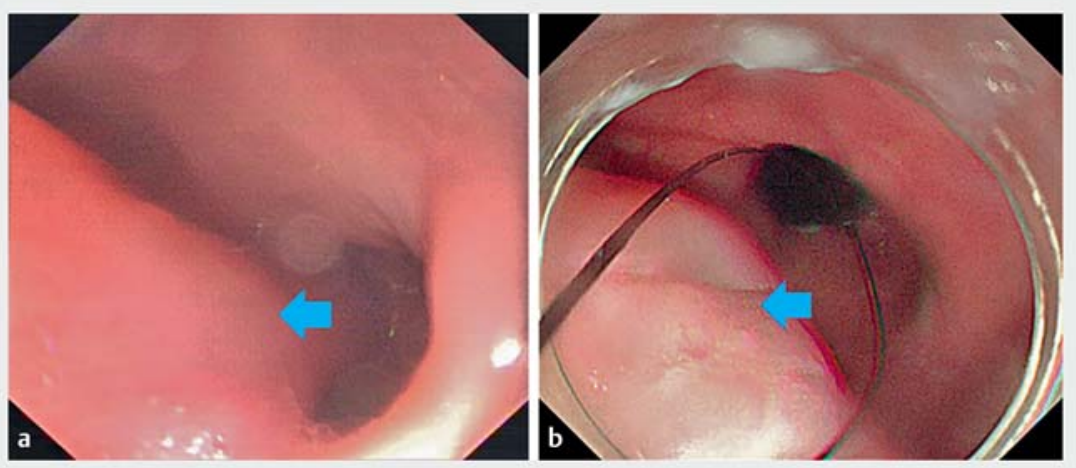

Fig. 2 Views on white-light endoscopy showing: a the long stalk (blue arrow); $\mathbf{b}$ the body of mass (blue arrow).

esophageal lipoma, namely mass regurgitation (fleshy tissue extruded from the mouth) [2]. When dealing with this kind of complex esophageal mass, complete examinations are necessary prior to treatment, and endoscopic treatment may possibly be able to achieve a curative effect.

Endoscopy_UCTN_Code_CCL_1AB_2AC_3AB
Funding

National Natural Science Foundation of China 81600424

Shanghai Hospital Development Center SHDC12016109 


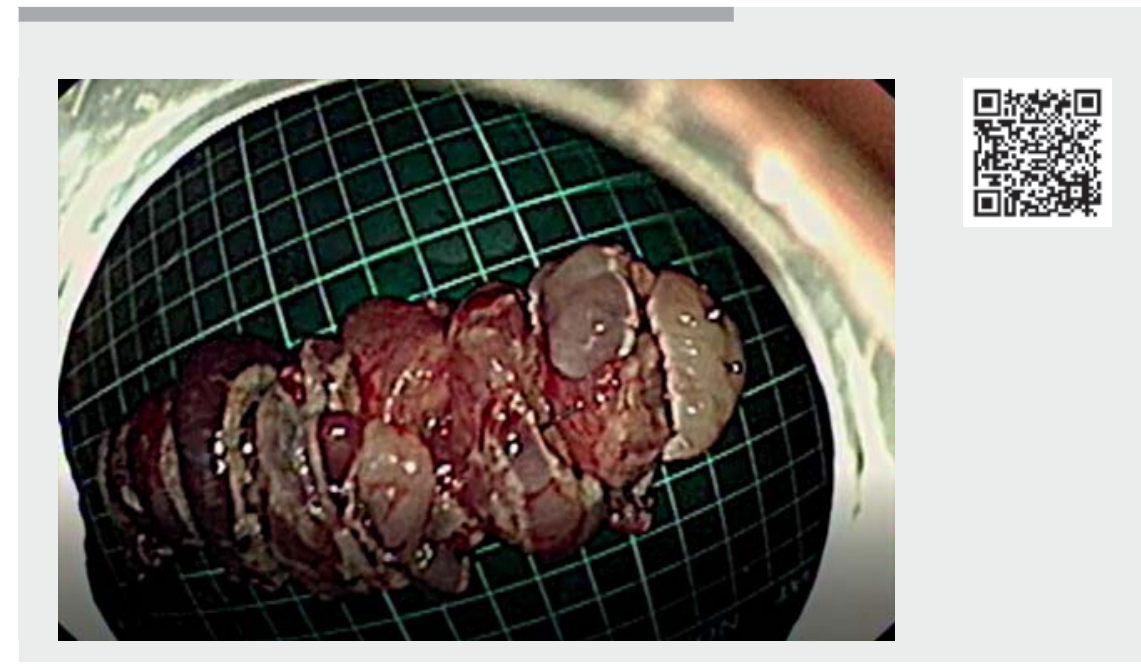

$\checkmark$ Video 1 Endoscopic submucosal dissection and hot snare resection was performed to remove a large tongue-like esophageal mass.

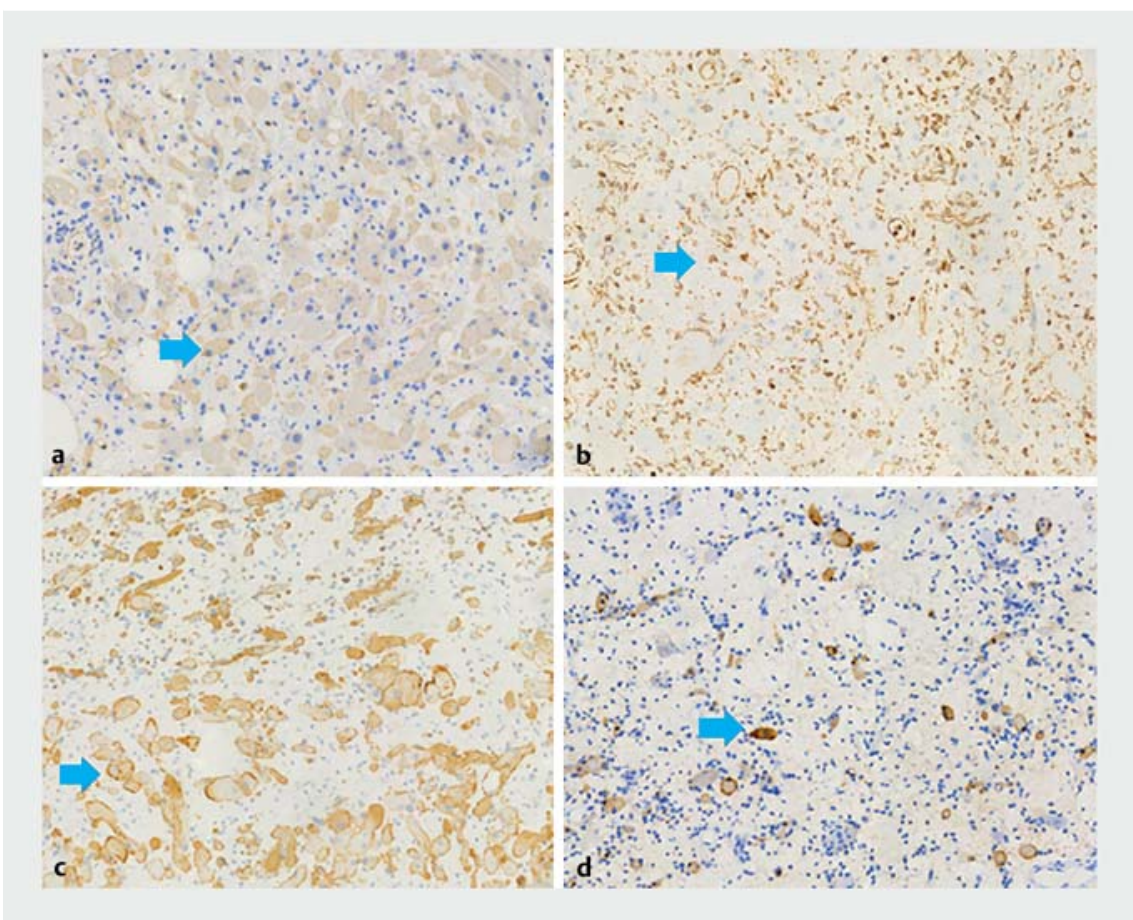

- Fig. 3 Images of immunohistochemical stainings which suggested striated muscle differentiation of this tumor (blue arrows indicated a striated cell): a positive for muscle-specific actin (MSA); $\mathbf{b}$ positive for vimentin; $\mathbf{c}$ strong positive for desmin; $\mathbf{d}$ positive for myoglobin.

\section{Competing interests}

The authors declare that they have no conflict of interest.
2 Department of pathology, Tongji Hospital, School of Medicine, Tongji University, Shanghai, China

\section{Corresponding author}

\section{Shuchang Xu, MD}

Department of Gastroenterology, Tongji Hospital, Tongji University School of Medicine, 389 Xincun Road, Shanghai 200065, China

xschang@163.com

\section{References}

[1] Ruiz-Mesa C, Goldberg JM, Coronado Munoz AJ et al. Rhabdomyosarcoma in adults: new perspectives on therapy. Curr Treat Options Oncol 2015; 16: 27

[2] Ferrari D, Bernardi D, Siboni S et al. Esophageal lipoma and liposarcoma: a systematic review. World J Surg 2021; 45: 225-234

Bibliography

Endoscopy 2022; 54: E631-E632

DOI $10.1055 / \mathrm{a}-1730-4038$

ISSN 0013-726X

published online 4.2.2022

(c) 2022. Thieme. All rights reserved. Georg Thieme Verlag KG, Rüdigerstraße 14, 70469 Stuttgart, Germany

\section{CORRECTION}

Endoscopic resection of a large tongue-like esophageal mass: a rare case of esophageal striated muscle tumor

Wang Z, Sun H, Zeng Y. Endoscopic resection of a large tongue-like esophageal mass: a rare case of esophageal striated muscle tumor. Endoscopy 2022, doi:10.1055/a-17304038

In the above-mentioned article, the institutions of the authors have been corrected. This was corrected in the online version on April 14, 2022. 